OPEN ACCESS

Edited by:

Daniel de Paiva Silva, Goiano Federal Institute (IFGOIANO),

Brazil

Reviewed by:

Thiago Vieira,

Federal University of Pará, Brazil

Jessie L. Knowlton,

Baraton College, Kenya

Yanping Wang,

Nanjing Normal University, China

${ }^{*}$ Correspondence:

Xitao Yang

1024807242@qq.com

Dongmei $Y u$

yudongmei50@163.com

Specialty section:

This article was submitted to Biogeography and Macroecology, a section of the journal

Frontiers in Ecology and Evolution

Received: 03 November 2021

Accepted: 30 December 2021

Published: 25 January 2022

Citation:

Yang X, Duan Z, Li S, Zhang C,

Qu M, Hua G, Niu X, Hu H and Yu D

(2022) Factors Driving the Abundance

of Wintering Waterbirds in Coastal

Areas of Guangdong Province, China.

Front. Ecol. Evol. 9:808105.

doi: $10.3389 /$ fevo.2021.808105

\section{Factors Driving the Abundance of Wintering Waterbirds in Coastal Areas of Guangdong Province, China}

\author{
Xitao Yang ${ }^{1 *}$, Zhizhao Duan ${ }^{2}$, Shuangshuang $\mathrm{Li}^{2}$, Chunxia Zhang ${ }^{3}$, Ming $\mathrm{Qu}^{3}$, \\ Guodong Hua ${ }^{3}$, Xiaonan $\mathrm{Niu}^{4}$, Huijian $\mathrm{Hu}^{5}$ and Dongmei Yu${ }^{5 *}$
}

\begin{abstract}
${ }^{1}$ College of Wildlife and Protected Area, Northeast Forestry University, Harbin, China, ${ }^{2}$ Xiyan Natural Resources Technology (Guangzhou) Co., Ltd., Guanghzou, China, ${ }^{3}$ Guangdong Forestry Survey and Planning Institute, Guanghzou, China, ${ }^{4}$ Huizhou Institute of Forestry, Huizhou, China, ${ }^{5}$ Guangdong Key Laboratory of Animal Conservation and Resource Utilization, Guangdong Public Laboratory of Wild Animal Conservation and Utilization, Institute of Zoology, Guangdong Academy of Sciences, Guangzhou, China
\end{abstract}

The diverse habitat of the coastal areas of Guangdong, China, supports important waterbird populations, thereby contributing to the conservation of waterbirds in China and globally. The sensitivity of different waterbirds to environmental driving factors results in differences in habitat selection, which in combination affect waterbird abundance. This study investigated the effects of environmental and human disturbance factors on the abundance of waterbirds based on a survey of waterbirds in coastal areas of Guangdong Province, China. Redundancy analysis (RDA) was mainly used to study the relationships between the abundance of waterbirds and environmental and human factors. The results showed that the areas of mangrove and tidal flats were the main factors driving the abundance of shorebirds and open water waterbirds, whereas the areas of mangrove and water bodies were the main factors driving the abundance of wading birds and waterfowl, respectively. Road length and the areas of construction land were found to have negative effects on the abundance of waterbirds. A waterbird protection and management strategy was proposed based on the results.

Keywords: waterbird, conservation, habitat, diversity, environmental factors

\section{INTRODUCTION}

Global waterbird diversity has shown a declining trend in recent decades, which has been attributed to a changing natural environment and human disturbance (Yasué, 2006; Ma et al., 2014; Hamza et al., 2015; Tavares et al., 2015; Wei et al., 2017; Jackson et al., 2021). A decline in waterbirds diversity has been particularly prominent in the coastal areas of China. The coastal wetlands of China host 230 waterbird species, accounting for over $25 \%$ of the global total. However, $\sim 19 \%$ of waterbirds abundance in China have suffered significant declines (Ma et al., 2014). Previous studies have shown that waterbirds in coastal areas are affected by environmental factors and human disturbance (Ge et al., 2006; Yasué, 2006; Hamza, 2020; Wang et al., 2020). These factors include the areas of water (Wang et al., 2020), mangrove (Acevedo and Aide, 2008; Huang et al., 2012; Mancini et al., 2018), tidal flat (Burger, 2018), and aquaculture ponds (Walton et al., 2015; Wei et al., 2017; Fonseca and Navedo, 2020; Wang et al., 2020), as well as roads and land for construction 
(Ma et al., 2014). An understanding of the key factors driving the abundance of waterbirds in coastal areas of China is important for adopting feasible waterbird conservation measures.

The same environmental and human disturbance factors may have very different effects on different waterbird guilds (Hamza et al., 2015; Tavares et al., 2015). Open water waterbirds are less sensitive to spatial changes in habitat characteristics compared to other groups (Hamza et al., 2015). Although mangroves may encroach on shorebird feeding grounds (Leung, 2015; Zhang et al., 2019), mangroves provide the optimal breeding ground for some large waders, such as herons (Etezadifar and Barati, 2013). While mudflats provide favorable habitat for curlew species (Dias et al., 2006), open mudflats may increase predation risk. In addition, while aquaculture ponds can provide potentially important feeding grounds for some shorebirds (Walton et al., 2015; Wei et al., 2017; Fonseca and Navedo, 2020; Wang et al., 2020), these ponds have detrimental effects on some other species. It is generally accepted that human activity may disturb some species, while having a beneficial effect on others, with shorebirds possibly benefitting from sediment generated by aquaculture since it allows them to forage more efficiently (Lunardi and Macedo, 2013). Different waterbirds show significantly different responses to environmental and human disturbance factors. Therefore, there is a need for models to help researchers to fully understand these differences. These efforts can provide guidance for future coastal waterbird conservation and habitat restoration.

The coastal areas of Guangdong Province, China, are rich in wetlands, including open beaches, vast mudflats, mangroves, estuaries, and aquaculture. In addition, this region is located along the "East Asia-Australia" migratory bird routes, thereby providing diverse habitat for supporting important waterbird populations (Zou et al., 2008; Zhang et al., 2019) and acting as an important stopover, breeding, and wintering habitat for endangered waterbirds (Hong et al., 2017). Therefore, the coastal areas of Guangdong Province play a key role in the protection of waterbirds in China and even globally. Many coastal wetlands within Guangdong Province have been identified as key bird protection areas, including Shenzhen Bay, Haifeng Wetland, Nansha Wetland, Na'nao Migratory Bird Reserve, and Zhanjiang Mangrove Reserve. However, changes to the ecological environment of the coastal areas of Guangdong Province resulting from disturbance by human activities over the past 40 years have resulted in a decline in ecological resources required by waterbird populations. Consequently, the sustainable development of resources required by waterbirds has come under increasing threat. Mitigating this decline is the basis of waterbird conservation in China and globally. However, further study of the factors driving the abundance of waterbirds in the coastal areas of Guangdong Province is required to develop effective waterbird conservation strategies.

The aim study was to investigate the effects of environmental and human disturbance factors on the abundance of waterbirds in the coastal areas of Guangdong province. (1) identifying the relationship between the abundance of wintering waterbirds and environmental and human factors;
(2) determining the effects of environmental and human factors on waterbirds guilds; and (3) identifying critical variables of waterbird abundance.

\section{METHODS AND STUDY SITE}

\section{Study Site}

Guangdong Province is in the southernmost part of mainland China, between latitude $20^{\circ} 13^{\prime}-25^{\circ} 31^{\prime}$ north and longitude $109^{\circ} 39^{\prime}-117^{\circ} 19^{\prime}$ east and is known to be a region of abundant light, heat, and water resources (Figure 1). The annual average precipitation in Guangdong Province is 1,300-2,500 $\mathrm{mm}$. This province also has the longest continental shoreline in China at $3,368.1 \mathrm{~km}$, including $1,288 \mathrm{~km}$ of muddy shoreline. Mangrove forests of $27,778.3 \mathrm{hm}^{2}$ are distributed along the coastline, accounting for approximately half of the mangrove forest area in China. In addition, Guangdong Province falls along the "East Asia-Australia" bird migratory route. Therefore, the province serves as a suitable waterbird stopover and feeding area during the winter migration. The coastal regions of Guangdong Province contain many aquaculture ponds and rapid economic development has increased the heterogeneity of the landscape, providing for a wide variety of habitats.

\section{Methods \\ Quadrats and Transects}

Previous studies have demonstrated that the foraging radii of most shorebirds do not exceed $5 \mathrm{~km}$ (Lange et al., 2018; Gutowsky et al., 2019). Therefore, the present study divided the coastal area of Guangdong Province into $10 \mathrm{~km} \times 10 \mathrm{~km}$ grids using the kilometer grid method, resulting in the establishment of 87 quadrants (Figure 1). A $6 \mathrm{~km}$ survey transect was set inside each quadrat.

\section{Waterbird Survey and Waterbirds Guilds}

The optimal period for conducting a shorebird species abundance survey is during low tide (Jimenez et al., 2015; Fonseca et al., 2017; Horn et al., 2020). Therefore, the present study scheduled shorebird surveys during low tide through consultation with the tide table on the official website of the China Maritime Services Network (Ocean.cnss.com.cn). The survey was conducted during daylight hours from December 2018 to February 2019, and from December 2019 to February 2020. A telescope (PENTAX-PF$65 \mathrm{ED}$ II) was used during the survey and scientific researchers with rich field experience and knowledge of bird identification participated in the field work. The book "A Field Guide to the Birds of China" was also consulted for the identification of bird species (MacKinnon and Phillipps, 2000). Data collected during the coastal winter waterbird survey in Guangdong Province from 2016 to 2018 were also included in the analysis.

Waterbirds were grouped into guilds reflecting the foraging habits and morphology of species (Hamza et al., 2015; Tavares et al., 2015). Four guilds of waterbirds were identified: (1) shorebirds, (2) wading birds, (3) open water waterbirds, and (4) waterfowl (Table 1). 


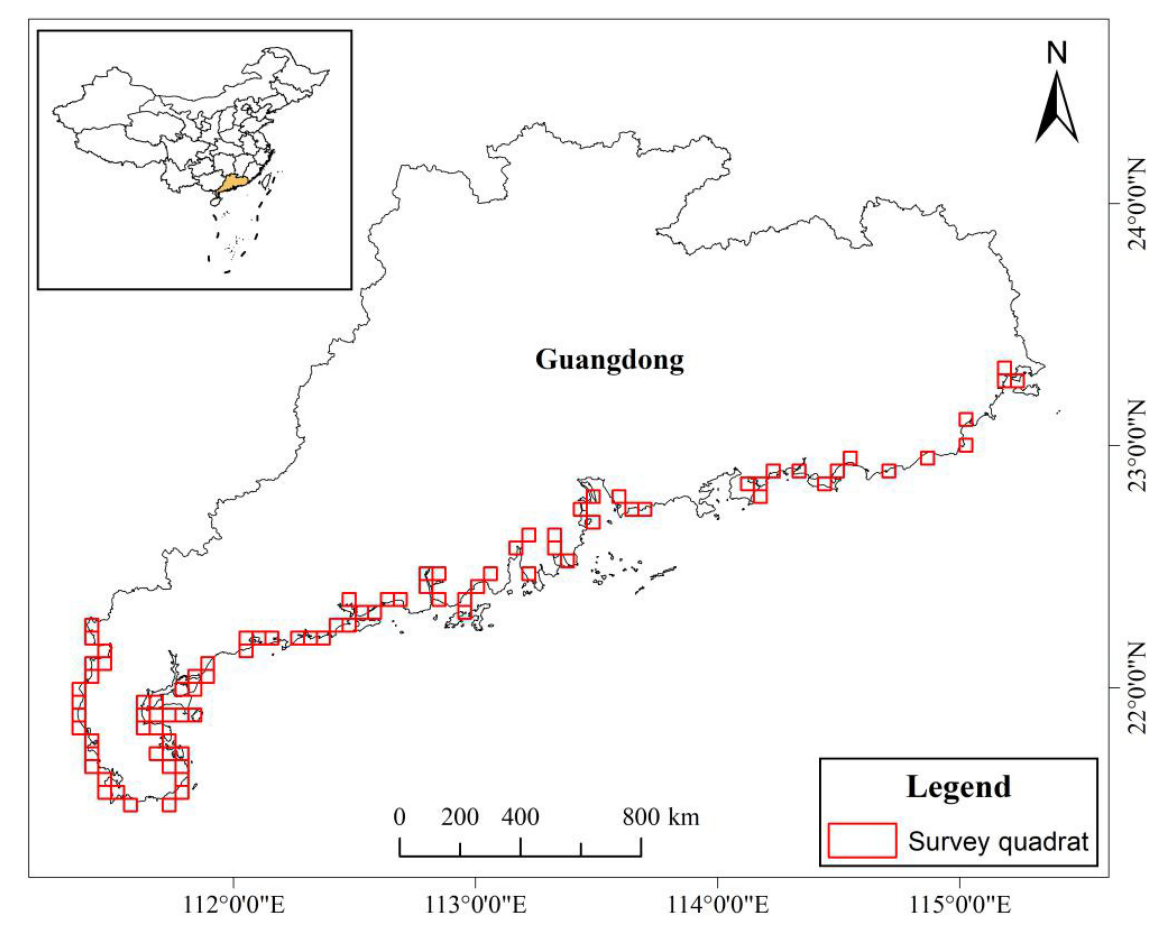

FIGURE 1 | Schematic diagram of Guangdong Province, China, showing locations of 87 coastal quadrat sampling survey points.

\section{Environmental and Anthropogenic Variables}

The simulation of the spatial abundance of species requires consideration of characteristic scales of habitat factors associated with different levels of organization of the species

TABLE 1 | List of waterbird species recorded during a field survey of coastal sites in Guangdong Province, China classified by foraging guilds.

\begin{tabular}{ll}
\hline Guild & Scientific name \\
\hline Shorebirds & Phalacrocorax pelagicus, Egretta sacra, Pluvialis squatarola, \\
& P. fulva, Charadrius alexandrines, C. dubius, C. mongolus, \\
& Numenius minutes, N. phaeopus, N. madagascariensis, \\
& N. arquata, Limosa limosa, L. lapponica, Tringa erythropus, \\
& T. tetanus, T. nebularia, T. ochropus, T. glareola, \\
& T. stagnatilis, T. guttifer, Actitis hypoleucos, Heteroscelus \\
& brevipes, Xenus cinereus, Eurynorhynchus pygmeus, \\
& Arenaria interpres, Limnodromus semipalmatus, Calidris \\
& ruficollis, C. alpine, C. temminckii, C. ferruginea, Crocethia \\
& alba, Himantopus himantopus, Recurvirostra avosetta, \\
& Haematopus ostralegus. \\
& Pelecanus onocrotalus, Ardea cinerea, A. intermedia, \\
& A. purpurea, Butorides striata, Ardeola bacchus, Bubulcus \\
& ibis, Egretta alba, E. garzetta, Nycticorax nycticorax, \\
& Ixobrychus sinensis, I. cinnamomeus, Botaurus stellaris, \\
& Gorsachius magnificus, Platalea leucorodia, P. mino. \\
Wading birds & Larus ridibundus, L. saundersi, L. crassirostris, Chlidonias \\
& hybrida, C. leucopterus, C. niger, Gelochelidon nilotica, \\
& Sterna caspia. \\
& Podiceps cristatus, Tachybaptus ruficollis, Phalacrocorax \\
carbo, Anas acuta, A. crecca, A. formosa, A. platyrhynchos, \\
A. poecilorhyncha, A. strepera, A. penelope, A.querquedula, \\
A. clypeata, Aythya marila, A. fuligula, Tadorna ferruginea, \\
T. tadorna,Dendrocygna javanica, Melanitta fusca, Gallinago \\
megala, G. stenura, G. gallinago, Eurasian Coot. \\
waterbirds
\end{tabular}

(Latimer et al., 2006). The present study considered positive and negative environmental impact factors. Considered positive environmental impact factors included the areas of mangroves, tidal flats, and water bodies, whereas negative environmental impacts included the areas of aquaculture ponds and construction land and the length of roads (Table 2).

The areas of mangrove forests, tidal flats, water bodies, and aquaculture ponds were identified from vector data obtained from the second Wetland Resource Survey of Guangdong Province $(30 \mathrm{~m} \times 30 \mathrm{~m}, 2017$, Guangdong Forestry Bureau). Remote-sensed multi-period land use/land cover data (30 $\mathrm{m} \times 30 \mathrm{~m}, 2018)$, and road data $(30 \mathrm{~m} \times 30 \mathrm{~m}, 2018)$ were provided by the Data Center for Resources and Environmental Sciences, Chinese Academy of Sciences (RESDC). ${ }^{1}$ These data were extracted from each quadrat using Arc GIS 10.02 and field corrected.

\section{Data Processing Methods Spatial Autocorrelation Analysis}

The present study applied Moran's I test in the $\mathrm{R}$ package to determine the presence of spatial autocorrelation (Cliff and Ord, 1981). Results display that most of the data showed non-significant spatial autocorrelation.

\section{Redundancy Analysis}

Redundancy analysis (RDA) was performed to reveal the factors that influenced the abundance of waterbirds (Gil-Tena et al.,

\footnotetext{
${ }^{1}$ http://www.resdc.cn
} 
TABLE 2 | Environmental and anthropogenic variables considered in the present study.

\begin{tabular}{|c|c|c|c|}
\hline Factor & Description of the habitat factor & Data type & Unit \\
\hline \multicolumn{4}{|l|}{$\begin{array}{l}\text { Environmental } \\
\text { factors }\end{array}$} \\
\hline Area of mangroves & The area of mangrove in quadrat. & Positive & $\mathrm{hm}^{2}$ \\
\hline Area of tidal flats & $\begin{array}{l}\text { The area of beach in quadrat, including } \\
\text { silt beach, sand beach, etc. }\end{array}$ & Positive & $\mathrm{hm}^{2}$ \\
\hline $\begin{array}{l}\text { Area of water } \\
\text { bodies }\end{array}$ & $\begin{array}{l}\text { The area of water in a quadrat, including } \\
\text { lakes, rivers, reservoirs, etc. }\end{array}$ & Positive & $\mathrm{hm}^{2}$ \\
\hline \multicolumn{4}{|l|}{$\begin{array}{l}\text { Anthropogenetic } \\
\text { factors }\end{array}$} \\
\hline $\begin{array}{l}\text { Area of aquaculture } \\
\text { ponds }\end{array}$ & The area of aquaculture in quadrat. & Positive & $\mathrm{hm}^{2}$ \\
\hline Road length & $\begin{array}{l}\text { Total length of road in each pixel. Road } \\
\text { includes primary highways, secondary } \\
\text { highways, improved roads, light-duty } \\
\text { paved roads, improved light-duty gravel } \\
\text { roads, and improved light-duty dirt } \\
\text { roads. }\end{array}$ & Negative & $\mathrm{km}$ \\
\hline Built-up land & $\begin{array}{l}\text { The land on which buildings and } \\
\text { structures are built were regarded as } \\
\text { urban and rural residential land and } \\
\text { public facilities. }\end{array}$ & Negative & $\mathrm{hm}^{2}$ \\
\hline
\end{tabular}

The data were gridded in Arc GIS 10.02 (10 km × $10 \mathrm{~km}$ pixels). The data were sourced from the second Wetland Resource Survey of Guangdong Province (2017, Guangdong Forestry Bureau) and the Data Center for Resources and Environmental Sciences, Chinese Academy of Sciences (RESDC; http://www.resdc.cn).

2015; Zhang et al., 2016; Wang et al., 2021). The specific methods were as follows:

(1) Standardization of assessment indicators

During RDA analysis, assessment indicators were considered as explanatory variables. Since explanatory variables did not share the same units, zero-mean normalization was applied using Canoco5.0 for uniformity of input data (Wang et al., 2021). Quantitative indices were standardized by the range method. The values of positive indices are proportional to the strength of their function. Eqs. (1 and 2) show the standardized calculations of positive and negative indicators.

$$
\begin{gathered}
Z_{i j}=\frac{X_{i j}-X_{j m i n}}{X_{j \max }-X_{j m i n}} \\
Z_{i j}=\frac{X_{j \max }-X_{i j}}{X_{j \max }-X_{j \min }}
\end{gathered}
$$

In Eqs. 1 and $2, \mathrm{Z}_{i j}$ is the standardized value of an environmental factor, ranging from 0 to $1, \mathrm{X}_{i j}$ is the $\mathrm{jth}$ value of index $\mathrm{i}, \mathrm{X}_{j \min }$ is the minimum value of index $\mathrm{i}$, and $\mathrm{X}_{j \max }$ is the maximum value of index $i$.

(2) Redundancy analysis

During RDA analysis, abundances of waterbirds were taken as response variables, and no data transformation was applied. The significance of canonical axes was evaluated using the Monte Carlo test with 499 permutations under the reduced model.

\section{RESULTS}

\section{Abundance of Waterbirds and Waterbird Guilds}

The survey conducted in the present study identified 80 species, accounting for $\sim 34.78 \%$ of coastal waterbird species ( 230 species) in China. The identified species were divided into four guilds: (1) shorebirds (34 species); (2) wading birds (17 species); (3) open water waterbirds (8 species), and (4) waterfowl (21 species) (Table 1).

Sixteen of the recorded species are listed in "China's National Key Protected Species List," including Xenus cinereus, Pelecanus onocrotalus, Larus saundersi, Tringa guttifer, Platalea leucorodia, and Limnodromus semipalmatus. Of the recorded species, 56 are listed in the "Agreement Between the Government of the People's Republic of China and the Government of Japan for the Protection of Migratory Birds and Habitat Environment" (1981), including Phalacrocorax pelagicus, Pluvialis squatarola, Numenius phaeopus, Ardea purpurea, Larus ridibundus, Anas acuta, and Gallinago megala etc. In addition, 32 of the recorded species are listed in the "Agreement Between the Government of the People's Republic of China and the Government of Australia for the Protection of Migratory Birds and Their Habitat Environment" (1986), including Egretta alba, Platalea leucorodia, Anas querquedula, Charadrius dubius, Numenius arquata, and Sterna caspias. The results of the field survey indicate that the coastal areas of Guangdong Province play a key role in protecting the biodiversity of waterbirds in China and around the world.

\section{Habitat Characteristics and Human Factors}

Table 3 shows a statistical summary of measured habitats and anthropogenic variables in the 87 sampled sites.

\section{Redundancy Analysis of Waterbird Abundance and Environmental Factors}

RDA was used to investigate the effects of environmental and human disturbance factors on the abundance of overwintering

TABLE 3 | A summary of ecological and anthropogenic factors influencing the

\begin{tabular}{|c|c|c|c|}
\hline Variable & Min. & Max. & Mean \pm standard error (SE) \\
\hline $\begin{array}{l}\text { The area of } \\
\text { mangroves }\left(\mathrm{hm}^{2}\right)\end{array}$ & 0 & $1,538.21$ & $139.79 \pm 242.87$ \\
\hline $\begin{array}{l}\text { The area of tidal } \\
\text { flats }\left(\mathrm{hm}^{2}\right)\end{array}$ & 0 & $3,265.59$ & $328.49 \pm 511.30$ \\
\hline $\begin{array}{l}\text { The area of water } \\
\text { bodies }\left(\mathrm{hm}^{2}\right)\end{array}$ & 0 & $5,717.87$ & $928.75 \pm 978.17$ \\
\hline $\begin{array}{l}\text { The area of } \\
\text { aquaculture ponds } \\
\left(\mathrm{hm}^{2}\right)\end{array}$ & 0 & $4,986.78$ & $974.92 \pm 1,038.99$ \\
\hline Road length (km) & 0 & $6,356.53$ & $720.03 \pm 1,074.05$ \\
\hline The area of built-up & 0 & 192.54 & $23.43 \pm 30.81$ \\
\hline
\end{tabular}
abundance of waterbirds in Guangdong Province, China. 
waterbirds, shorebirds, wading birds, open water waterbirds, and waterfowl, with the results shown in Supplementary Appendix 1.

For all waterbirds, the cumulative explanation of the variances of the species-environment relationship for all typical axes was 95.19\%. Monte Carlo permutation tests for all positive axes were significant $(F=3.1, P=0.002)$. The eigenvalues of the first two canonical axes far exceeded those of the other axes, indicating that these two axes were the main explanatory axes, explaining $\sim 47.48$ and $31.75 \%$ of variation by axis 1 and axis 2 , respectively. This result indicated that the first two typical axes explained most of the relationship between species and environmental variables.

Similar results were obtained for the other waterbirds guilds, with the cumulative explanation of variances of the speciesenvironment relationship for all typical axes exceeding $95 \%$ and a significant result of the Monte Carlo alignment test $(P<0.005)$. The first two typical axes explained most of the relationship between species and environmental variables.

\section{Relationships Between Waterbirds and Habitat Characteristics}

The areas of mangrove and tidal flats had positive influences on the abundance of all waterbirds (Figure 2A); the areas of mangroves and tidal flats were the main factors driving the abundance of shorebirds (Figure 2B); the area of mangroves was the main factor driving the abundance of wading birds (Figure 2C); the areas of mangroves and tidal plain were important factors driving the abundance of open water waterbirds (Figure 2D); the area of water was an important factor driving the abundance of waterfowl (Figure 2E).

\section{DISCUSSION}

The coastal areas of Guangdong Province support a variety of waterbird populations with different ecological needs (Zou et al., 2008; Zhang et al., 2019). Therefore, the province provides an important habitat for many endangered waterbirds and plays a key role in the protection of waterbirds to China and globally. The different waterbird guilds show preferences for different environmental factors, leading to differences in habitat selection. Consequently, the combination of multiple driving factors affects the abundance of waterbirds. Identifying the main factors driving the abundance of coastal waterbirds in Guangdong Province is therefore of great consequence for developing effective waterbirds conservation measures.

\section{Driving Factors}

An analysis of the factors influencing the abundance of all waterbirds in Guangdong Province found that the areas of mangroves, tidal flats, water bodies, and aquaculture ponds had positive impacts on most waterbirds, whereas the length of roads and the area of construction land had negative impacts on most waterbirds.

As shown in Figure $\mathbf{2 A}$, the areas of mangrove and tidal flats were the main factors driving the abundance of waterbirds. The area of mangrove was positively correlated with waterbird abundance up until a certain threshold of area (Zou et al., 2008), above which the abundance of waterbirds decreased. This result can be attributed to the encroachment of mangroves on tidal flats, which some waterbirds rely on for food (Leung, 2015; Zhang et al., 2019). Tidal flats are a rich source of food for some waterbirds (Burger, 2018), with the area of tidal flat positively correlated with benthic organism abundance (Fonseca et al., 2017). However, foraging by waterbird abundance in open tidal flats typically increases their vulnerability to human disturbance (Dias et al., 2006). In contrast, mangroves can shield waterbirds from human disturbance (Ma et al., 2010; Zhang et al., 2019). Therefore, there is an ideal trade-off between areas of tidal flats and mangroves that provide food and shelter to waterbirds, respectively. Some studies have suggested a ratio of tidal flat area to mangrove area in the coastal areas of Guangdong, China, of $\sim 4: 1$, which is conducive to the protection of waterbirds (Yang et al., 2021). Because of this interplay between mangrove and tidal flat areas, these have become the main factors driving the abundance of waterbirds.

The area of water bodies is another key factor driving the abundance of waterbirds. A water body with a large area and shallow depth of $0.1-2 \mathrm{~m}$ can provide a complex habitat for waterbirds, thereby meeting the habitat requirements of many waterbirds, including small waders, large waders, rangers, and pochards (Zhang et al., 2016; Wei et al., 2017). In addition, the likelihood of sediment exposure increases with increasing waterbody area, thereby attracting more waterbirds (Wei et al., 2017). The rainy season in the coastal areas of Guangdong Province occurs over summer, which is conducive to the enrichment and exposure of nutrients. The transition to winter results in the gradual formation of a large area of shallow water, exposing nutrient-rich sediment, which provides optimal waterbird foraging areas.

The area of aquaculture ponds was also found to be an important factor driving the abundance of waterbirds. Aquaculture practices can result in the production of artificial waterbird habitats, which fulfill an important role for some waterbirds (Yasué and Dearden, 2009; Lehnen and Krementz, 2013; Navedo et al., 2013; Fonseca and Navedo, 2020). As the main habitat for waterbirds, the supratidal region hosts high densities of foraging waterbirds (Mander et al., 2007; Ehmke et al., 2016). Large areas of aquaculture ponds in these supratidal habitats can provide alternative or complementary feeding habitats for migratory waterbirds at all life stages (Walton et al., 2015; Wei et al., 2017; Fonseca and Navedo, 2020; Wang et al., 2020). Fish and shrimp left over from harvested aquaculture ponds can be an important source of food for waterbirds.

Finally, road length and area of construction land had negative impacts on the abundance of waterbirds. The coastal area of Guangdong Province supports waterbirds as well as human development. In particular, the increases in the length of road and area of construction land have resulted in the encroachment of habitat suitable for waterbirds (Ma et al., 2014). Human disturbance has resulted in the loss of suitable habitat for waterbirds, which in most cases will have negative impacts on the abundance of waterbirds, with only a few waterbirds showing a low sensitivity to anthropogenic disturbances. 

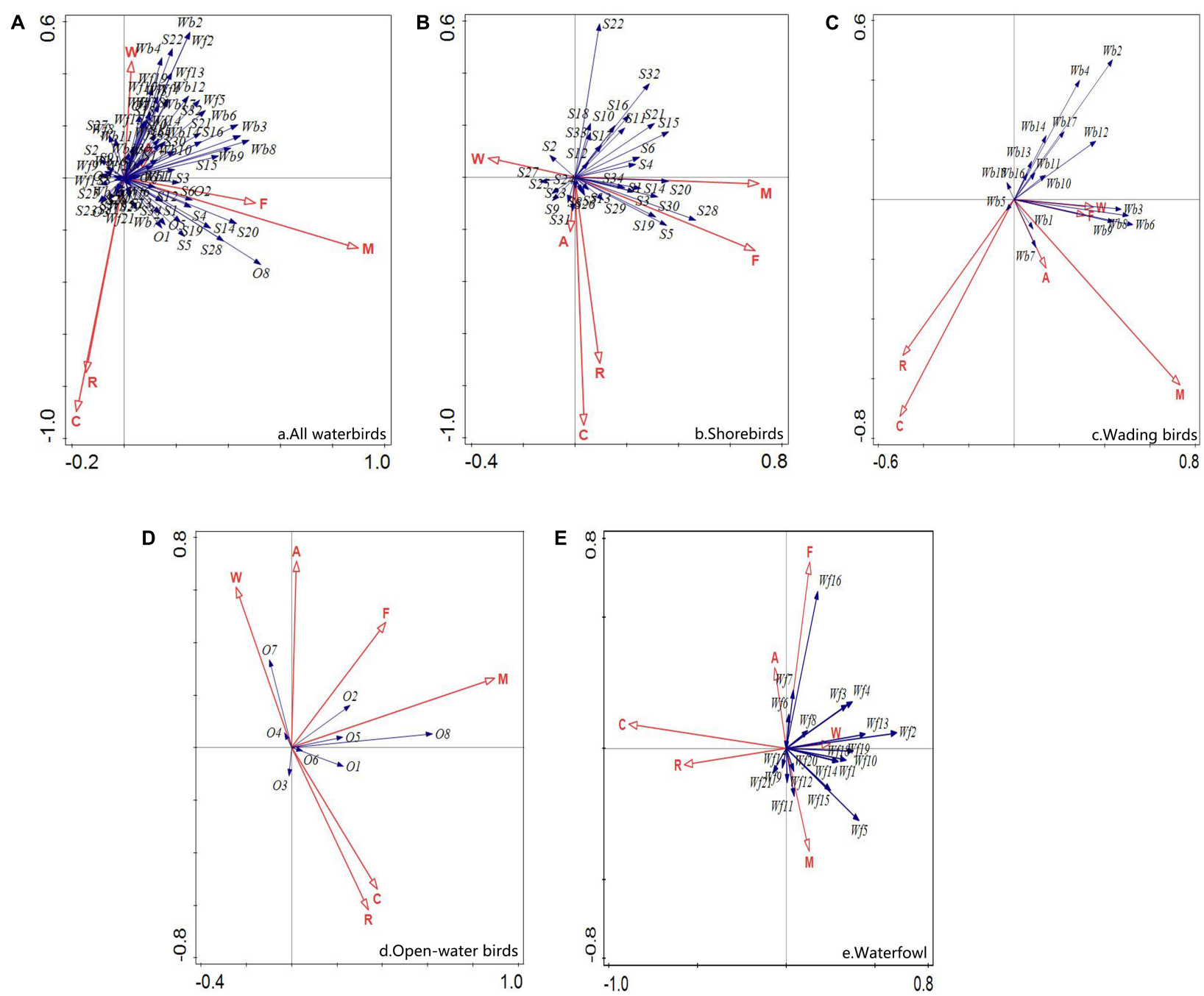

FIGURE 2 | RDA biplot of habitat variables and the abundances of waterbird. The red arrows indicate environment factors, the blue lines indicate species factors, and the length of each arrow indicates the strength of the relationship between an environmental factor and abundance. The angle of the arrow indicates the strength of the environmental factor. Explanatory variables: $\mathrm{M}$, the area of mangroves $\left(\mathrm{hm}^{2}\right) ; \mathrm{F}$, the area of tidal flats $\left(\mathrm{hm}^{2}\right)$; $\mathrm{W}$, the area of water bodies $\left(\mathrm{hm} \mathrm{m}^{2}\right)$, A, the area of aquaculture ponds $\left(\mathrm{hm}^{2}\right)$; R, road length $(\mathrm{km})$; B, the area of built-up land $\left(\mathrm{hm}^{2}\right)$. (A) Biplot of habitat variables and the abundances of all waterbirds. (B) Biplot of habitat variables and the abundances of shorebirds. Shorebirds: S1-Pelecanus crispus, S2-Egretta sacra, S3-Pluvialis squatarola, S4-P. fulva, S5-Charadrius alexandrines, S6-C. dubius, S7-C. mongolus, S8-Numenius minutes, S9-N. phaeopus, S10-N. madagascariensis, S11-N. arquata, S12-Limosa limosa, S13-L. lapponica, S14-Tringa erythropus, S15-T. tetanus, S16-T. nebularia, S17-T. ochropus, S18-T. glareola, S19-T. stagnatilis, S20-T. guttifer, S21-Scolopax rusticola, S22-Heteroscelus brevipes, S23-Xenus cinereus, S24-Eurynorhynchus pygmeus, S25-Arenaria interpres, S26-Limnodromus semipalmatus, S27-Calidris ruficollis, S28-C. alpine, S29-C. temminckii, S30-C. ferruginea, S31-C. alba, S32-Himantopus himantopus, S33-Recurvirostra avosetta, S34-Haematopus ostralegus. (C) Biplot of habitat variables and the abundances of wading birds. Wading birds: Wb1-Pelecanus onocrotalus, Wb2-Phalacrocorax carbo, Wb3-Ardea cinerea, Wb4-A. purpurea, Wb5-Butorides striata, Wb6-Ardeola bacchus, Wb7-Bubulcus ibis, Wb8-Egretta alba, Wb9-E. garzetta, Wb10-Ardea intermedia, Wb11-Nycticorax nycticorax, Wb12-Ixobrychus sinensis, Wb13-I. cinnamomeus, Wb14-Botaurus stellaris, Wb15-Gorsachius magnificus, Wb16-Platalea leucorodia, Wb17-P. mino. (D) Biplot of habitat variables and the abundances of open water waterbirds. Open water waterbirds: O1-Larus ridibundus, O2-Chlidonias hybrid, O3-C. leucopterus, O4-C. niger, O5-Larus saundersi, O6-Gelochelidon nilotica, O7-Sterna caspia, O8-Larus crassirostris. (E) Biplot of habitat variables and the abundances of waterfowl. Waterfowl: Wf1-Great Crested Grebe, Wf2-Tachybaptus ruficollis, Wf3-Eurasian Coot, Wf4-Anas acuta, Wf5-A. crecca, Wf6-A. formosa, Wf7-A. platyrhynchos, Wf8-A. poecilorhyncha, Wf9-A. strepera, Wf10-A. penelope, Wf11-A. querquedula, Wf12-A. clypeata, Wf13-Aythya marila, Wf14-A. fuligula, Wf15-Tadorna ferruginea, Wf16-T. tadorna, Wf17-Dendrocygna javanica, Wf18-Melanitta fusca, Wf19-Gallinago megala, Wf20-G. stenura, Wf21-G. gallinago.

\section{Factors Driving the Abundance of Different Waterbird Guilds}

The areas of mangroves and tidal flats were the main factors driving the abundance of shorebirds. The plover and sandpiper species make up most shorebirds. Most shorebirds are migratory, small in size, and mainly inhabit tidal flat environments with mangrove vegetation (Zou et al., 2008). Mangroves provide refuge functions for shorebirds (Ikuta and Daniel, 2003; Thompson and Rog, 2019; Zhang et al., 2019), including shielding them from human activity (Ma et al., 2010; Zhang et al., 2019). Mudflats in contrast provide rich food resources for shorebirds 
(Mander et al., 2007; Burger, 2018). The ebbing tide results in the stranding of invertebrates, thereby providing rich food resources for foraging shorebirds (Jimenez et al., 2015). For the above reasons, the areas of mangrove and tidal flats have an important impact on the abundance of shorebirds.

The area of mangrove was the main factor influencing the abundance of wading birds. The wading waterbirds are mainly egret species. These egret species are relatively large and prefer to nest in mangroves (Etezadifar and Barati, 2013). Larger areas of mangrove tend to be more attractive to egrets.

The areas of mangrove and tidal flats were the main factors driving the abundance of open water waterbirds. These open water waterbirds are mainly gull species, and as migratory birds, they mainly gather in the tidal flat environment with mangrove vegetation cover. A significant positive correlation between the composition of gulls and the density of macrobenthos has previously been demonstrated in the forest area of Minjiang River, Fujian Province of China (Lin, 2003). The composition and density of macrobenthos were significantly correlated with the areas of mangrove and tidal flats (Zou et al., 2008). Therefore, the areas of mangrove and tidal flats were key factors affecting the abundance of gulls.

The area of water bodies was found to be a key factor driving the abundance of waterfowl. The identified waterfowl were mostly goose and duck species. These species require large areas of water that can provide a complex water environment and rich food resources (Zhang et al., 2016; Wei et al., 2017). Food resources provided by large areas of water in Guangdong Province include the seeds, bulbs, and roots of Scirpus mariqueter and the tender roots and leaves of other aquatic plants.

\section{MEASURES NEEDED FOR WATERBIRD CONSERVATION}

The conservation of waterbirds requires consideration of the needs of various waterbird guilds, as explained below.

(1) Restoration of mangroves in the coastal areas of Guangdong Province in combination with the maintenance of a certain area of tidal flats.

The Chinese government has issued the Special Action Plan for Mangrove Conservation and Restoration (2020-2025) with the aim of protecting and restoring the coastal mangrove ecosystem in Guangdong Province. It is hoped that this plan can result in the restoration of 18,800 ha of mangrove forest nationally by 2025 , with 8,000 ha restored in Guangdong Province, $42.55 \%$ of the national total. Although this plan is an important measure for waterbird conservation, the ratio of beach area to mangrove area should be maintained at approximately 4:1 to maintain the maximum abundance of waterbirds in the region (Yang et al., 2021). This ratio between areas of mangrove and tidal flat is required since mangrove can erode the habitats of non-mangrove waterbird species (Zhai et al., 2019), thereby reducing waterbird biodiversity (Lewis, 2005) or affecting the patterns of utilization of mangrove ecosystems by waterbirds in a variety of ways (Kober and Bairlein, 2009; Huang et al.,
2012; Lunardi et al., 2012). For example, waterbirds that depend on mudflats for food and shelter may be detrimentally affected by the encroachment of mangroves (Leung, 2015; Zhang et al., 2019).

(2) The formulation of effective engineering measures to adjust hydrological processes in appropriate coastal areas of Guangdong Province.

Many coastal wetlands in Guangdong Province have been identified as key waterbird protection areas, including Shenzhen Bay, Haifeng Wetland, Nansha Wetland, Nanao Migratory bird Reserve, and Zhanjiang Mangrove Reserve. The artificial control of regional water levels is necessary to maintain depths and areas of waterbodies that are suitable for waterbirds. These measures are relevant to areas of open water regulated by hydrological control facilities such as sluices and embankments. Therefore, a rational hydrological regulation mechanism should be established to artificially regulate the areas and depths of water bodies according to the habitat requirements of resident waterbird communities.

(3) The establishment of aquaculture facilities in coastal areas and a gradual shift from intensive aquaculture to traditional aquaculture to provide alternative or complementary feeding habitats for migratory waterbirds.

Aquaculture ponds can act as important artificial habitats for many waterbirds (Yasué and Dearden, 2009; Lehnen and Krementz, 2013; Navedo et al., 2013; Fonseca and Navedo, 2020). The coastal supratidal area is the main habitat of waterbirds and hosts high densities of foraging waterbirds (Mander et al., 2007; Ehmke et al., 2016). The breeding mode of traditional aquaculture in the coastal regions of Guangdong Province relies on the ebb and flow of the tide to seed the ponds with fish and shrimp. This mode of aquaculture differs from intensive aquaculture as some fish and other sea life are left in the aquaculture ponds after the harvest. These leftover resources can act as complementary sources of food for migratory waterfowls. However, these traditional aquaculture methods are gradually shifting to intensive aquaculture (Guangdong Rural Statistical Yearbook). ${ }^{2}$ Intensive aquaculture does not allow the foraging of waterbirds in aquaculture ponds. Therefore, there is a need to establish a sound mode of aquaculture in the coastal areas of Guangdong Province that maintains benefits to migratory waterbirds. Operators of intensive aquaculture ponds should be encouraged to transition to traditional aquaculture to increase feeding habitat for waterbirds.

(4) The establishment of sound laws and regulations to protect the habitats of waterbirds from human activities.

Guangdong Province is currently undergoing rapid economic development. There have been increases in road length and area of construction land in coastal areas, thereby greatly encroaching on suitable waterbirds habitat. Therefore, there is an urgent need for regulatory authorities and environmental protection agencies to formulate relevant laws or regulations to protect waterbirds habitats from human activities, and particularly from human activities that may alter tidal flats and hydrological regimes.

\footnotetext{
${ }^{2}$ http://stats.gd.gov.cn/
} 


\section{CONCLUSION}

The present study investigated the effects of environmental and human disturbance on the abundance of waterbirds in coastal areas of Guangdong Province based on a field survey. The areas of mangrove and tidal flats were the main factors driving the abundance of shorebirds and open water waterbirds, whereas the areas of mangrove and water bodies were the main factors driving the abundance of wading birds and waterfowl, respectively. Road length and construction land were found to have negative effects on the abundance of waterbirds. Therefore, the conservation of waterbirds requires consideration of the needs of various waterbird guilds.

\section{DATA AVAILABILITY STATEMENT}

The original contributions presented in the study are included in the article/Supplementary Material; further inquiries can be directed to the corresponding author/s.

\section{ETHICS STATEMENT}

Ethical review and approval were not required for the animal study because our research is based on biodiversity research and does not involve wildlife ethics.

\section{AUTHOR CONTRIBUTIONS}

XY completed the manuscript. ZD, SL, CZ, MQ, and GH completed the field data collection and collation. $\mathrm{XN}, \mathrm{HH}$, and

\section{REFERENCES}

Acevedo, M. A., and Aide, T. M. (2008). Bird community dynamics and habitat associations in karst, mangrove and pterocarpus forest fragments in an urban zone in Puerto Rico. Caribb. J. Sci. 44, 402-416. doi: 10.18475/cjos.v44i3.a15

Burger, J. (2018). Use of intertidal habitat by four species of shorebirds in an experimental array of oyster racks, reefs and controls on Delaware Bay, New Jersey: avoidance of oyster racks. Sci. Total Environ. 624, 1234-1243. doi: 10.1016/j.scitotenv.2017.12.188

Cliff, A. D., and Ord, J. K. (1981). Spatial Processes-Models and Applications. London: Pion.

Dias, M. P., José, P. G., Miguel, L., Carlos, D. S., and Jorge, M. P. (2006). Distance to high-tide roosts constrains the use of foraging areas by dunlins: implications for the management of estuarine wetlands. Biol. Conserv. 131, 446-452. doi: 10.1016/j.biocon.2006.02.020

Ehmke, G., Grainne, S. M., Tomas, B., Daniel, I., and Michael, A. W. (2016). An obligate beach bird selects sub-, inter- and supra-tidal habitat elements. Estuar. Coast. Shelf Sci. 181, 266-276. doi: 10.1016/j.ecss.2016.08.050

Etezadifar, F., and Barati, A. (2013). Nest-site selection of Western Reef Heron (Egretta gularis) in relation to mangrove (Avicennia marina) structure in the Persian Gulf: implication for management. For. Ecol. Manag. 310, 74-79. doi: 10.1016/j.foreco.2013.07.060

Fonseca, J., Enzo, B., David, S., and Juan, G. N. (2017). Effects of tidal cycles on shorebird distribution and foraging behaviour in a coastal tropical wetland: insights for carrying capacity assessment. Estuar. Coast. Shelf Sci. 198, 279-287. doi: $10.1016 /$ j.ecss.2017.09.016

Fonseca, J., and Navedo, J. G. (2020). Shorebird predation on benthic invertebrates after shrimp-pond harvesting: implications for semi-intensive aquaculture
DY completed the data analysis. All authors contributed to the article and approved the submitted version.

\section{FUNDING}

This work has received support from the Guangdong Basic and Applied Basic Research Foundation (2021A1515011282), Foerstry Administration of Guangdong Province (DFGP Project of Fauna of Guangdong-202115), GDAS Special Project of Science and Technology Development (2019GDASYL0105045), and GDAS Special Project of Science and Technology Development (2018GDASCX-0107).

\section{ACKNOWLEDGMENTS}

We would like to thank all the reviewers who participated in the review and MJEditor (www.mjeditor.com) for their linguistic assistance during the preparation of this manuscript.

\section{SUPPLEMENTARY MATERIAL}

The Supplementary Material for this article can be found online at: https://www.frontiersin.org/articles/10.3389/fevo.2021. 808105/full\#supplementary-material

Supplementary Appendix 1 | Results of redundancy analysis (RDA) of the relationship between waterbird abundance and environmental factors in coastal regions of Guangdong Province, China.

management. J. Environ. Manag. 262:110290. doi: 10.1016/j.jenvman.2020. 110290

Ge, Z., Wang, T., Zhou, X., and Shi, W. (2006). Seasonal change and habitat selection of shorebird community at the South Yangtze River Mouth and North Hangzhou Bay, China. Acta Ecol. Sin. 26, 40-47. doi: 10.1016/s1872-2032(06) 60004-8

Gil-Tena, A., Miquel, D. C., Aude, E., Alain, B., Lluís, B., Burel, F., et al. (2015). Agricultural landscape composition as a driver of farmland bird diversity in Brittany (NW France). Agric. Ecosyst. Environ. 205, 79-89. doi: 10.1016/j.agee. 2015.03.013

Gutowsky, S. E., Ronconi, R., Gutowsky, L., Elderkin, M., Paquet, J., Mills, P. M., et al. (2019). Winter habitat associations of Purple Sandpiper (Calidris maritima) and Harlequin Duck (Histrionicus histrionicus) in Atlantic Canada. Estuar. Coast. Shelf. 222, 214-225. doi: 10.1016/j.ecss.2019.04.024

Hamza, F. (2020). Impacts of human activities on diversity of wintering waterbirds: assessment in Mediterranean coastal area. Ocean Coast. Manag. 198:105317. doi: 10.1016/j.ocecoaman.2020.105317

Hamza, F., Abdessalem, H., and Slaheddine, S. (2015). Species richness patterns of waterbirds wintering in the gulf of Gabès in relation to habitat and anthropogenic features. Estuar. Coast. Shelf Sci. 165, 254-260. doi: 10.1016/j. ecss.2015.05.025

Hong, Y., Ma, M., Thompson, J. R., and Flower, R. J. (2017). Protect coastal wetlands in China to save endangered migratory birds. Proc. Natl. Acad. Sci. U.S.A. 114:E5491. doi: 10.1073/pnas.1706111114

Horn, S., Schwemmer, P., Mercker, M., Enners, L., Asmus, R., Garthe, S., et al. (2020). Species composition of foraging birds in association with benthic fauna in four intertidal habitats of the Wadden Sea. Estuar. Coast. Shelf Sci. 233:106537. 
Huang, S., Shang, S., Yi, S., Chang, P., and Hwey, L. (2012). Restoration of shorebird-roosting mudflats by partial removal of estuarine mangroves in Northern Taiwan. Restorat. Ecol. 20, 76-84. doi: 10.1111/j.1526-100X.2010. 00744.x

Ikuta, L. A., and Daniel, T. B. (2003). Do fences protect birds from human disturbance? Biol. Conserv. 112, 447-452. doi: 10.1016/s0006-3207(02)00324-5

Jackson, M. V., Fuller, R. A., Gan, X., Li, J., and Choi, C. Y. (2021). Dual threat of tidal flat loss and invasive Spartina alterniflora endanger important shorebird habitat in coastal mainland China. J. Environ. Manag. 278:111549. doi: 10.1016/ j.jenvman.2020.111549

Jimenez, A., Robert, W. E., Corinna, F., Karen, R., and Ronald, C. Y. (2015). Intertidal biofilm distribution underpins differential tide-following behavior of two sandpiper species (Calidris mauri and Calidris alpina) during northward migration. Estuar. Coast. Shelf Sci. 155, 8-16. doi: 10.1016/j.ecss.2014.12.038

Kober, K., and Bairlein, F. (2009). Habitat choice and niche characteristics under poor food conditions. a study on migratory nearctic shorebirds in the intertidal flats of Brazil. Ardea 97, 31-42. doi: 10.5253/078.097.0105

Lange, C. J., Daniel, P. C., Kristine, L. M., and Bart, M. B. (2018). Predicting impacts of sea level rise on wintering redhead ducks along the lower Texas Coast. Glob. Ecol. Conserv. 16:e0481. doi: 10.1016/j.gecco.2018.e00481

Latimer, A. M., Wu, S., and Gja, S. (2006). Building statistical models to analyze species distributions. Ecol. Appl. 16, 33-50. doi: 10.1890/04-0609

Lehnen, S. E., and Krementz, D. G. (2013). Use of aquaculture ponds and other habitats by autumn migrating shorebirds along the lower Mississippi River. Environ. Manag. 52, 417-426. doi: 10.1007/s00267-013-0087-8

Leung, J. Y. S. (2015). Habitat heterogeneity affects ecological functions of macrobenthic communities in a mangrove: implication for the impact of restoration and afforestation. Glob. Ecol. Conserv. 4, 423-433. doi: 10.1016/j. gecco.2015.08.005

Lewis, R. (2005). Ecological engineering for successful management and restoration of mangrove forests. Ecol. Eng. 24, 403-418. doi: 10.1016/j.ecoleng. 2004.10.003

Lin, Q. X. (2003). Study on the Relationship Between Birds and Macrobenthos in Coastal Mangrove Forests of Southern Fujian. Ph. D. Dissertation. China: Xiamen University.

Lunardi, V. O., and Macedo, R. H. (2013). Shorebirds can adopt foraging strategies that take advantage of human fishing practices. EMU 114, 50-60. doi: 10.1071/ mu12097

Lunardi, V. O., Regina, H. M., José, P. G., and Jorge, M. P. (2012). Migratory flows and foraging habitat selection by shorebirds along the northeastern coast of Brazil: the case of Baía de Todos os Santos. Estuar. Coast. Shelf Sci. 96, 179-187. doi: 10.1016/j.ecss.2011.11.001

Ma, Z., Cai, Y., Li, B., and Chen, J. (2010). Managing wetland habitats for waterbirds: an international perspective. Wetlands 30, 15-27. doi: 10.1007/ s13157-009-0001-6

Ma, Z., Melville, D. S., Liu, J., Chen, Y., Yang, H., Ren, W., et al. (2014). Ecosystems management rethinking China's new great wall. Science 346, 912-914. doi: 10. $1126 /$ science. 1257258

MacKinnon, J., and Phillipps, K. (2000). A Field Guide to the Birds of China. Oxford: Oxford University Press.

Mancini, P. L., Armando, S. R., Luciano, G. F., Luís, F. S., and Yara, S. N. (2018). Differences in diversity and habitat use of avifauna in distinct mangrove areas in São Sebastião, São Paulo, Brazil. Ocean Coast. Manag. 164, 79-91. doi: 10. 1016/j.ocecoaman.2018.02.002

Mander, L., Nicholas, D. C., James, A., and Krysia, M. (2007). Assessing the development of newly created habitat for wintering estuarine birds. Estuar Coast. Shelf Sci. 75, 163-174. doi: 10.1016/j.ecss.2007.04.028

Navedo, J. G., Arranz, D., Herrera, A. G., Salmón, P., Juanes, J. A., and Masero, J. A. (2013). Agroecosystems and conservation of migratory waterbirds: importance of coastal pastures and factors influencing their use by wintering shorebirds. Biodiv. Conserv. 22, 1895-1907. doi: 10.1007/s10531-0130516-2

Tavares, D. C., Demétrio, L. G., Jailson, F. M., Salvatore, S., and Agostino, M. (2015). Environmental and anthropogenic factors structuring waterbird habitats of tropical coastal lagoons: implications for management. Biol. Conserv. 186, 12-21. doi: 10.1016/j.biocon.2015.02.027
Thompson, B. S., and Rog, S. M. (2019). Beyond ecosystem services: using charismatic megafauna as flagship species for mangrove forest conservation. Environ. Sci. Policy 102, 9-17. doi: 10.1016/j.envsci.2019.09.009

Walton, M. E. M., Vilas, C., Cañavate, J. P., Gonzalez, E., Prieto, A., Bergeijk, S., et al. (2015). A model for the future: ecosystem services provided by the aquaculture activities of Veta la Palma, Southern Spain. Aquaculture 448, 382-390. doi: 10.1016/j.aquaculture.2015.06.017

Wang, C., Wang, G., Dai, L., Liu, H., Li, Y., Qiu, C., et al. (2021). Study on the effect of habitat function change on waterbird diversity and guilds in Yancheng coastal wetlands based on structure-function coupling. Ecol. Indic. 122:107223.

Wang, C., Wang, G., Dai, L., Liu, H., and Zhao, Y. (2020). Diverse usage of waterbird habitats and spatial management in Yancheng coastal wetlands. Ecol. Indic. 117:106583. doi: 10.1016/j.ecolind.2020.106583

Wei, P., Zan, Q., Nora, F. Y. T., Paul, K. S. S., Cheung, S. G., and Li, M. (2017). Impact of habitat management on waterbirds in a degraded coastal wetland. Mar. Pollut. Bull. 124, 645-652. doi: 10.1016/j.marpolbul.2017. 02.068

Yang, X., Duan, Z., Hu, Y., Liu, J., Xu, Y., Hu, H., et al. (2021). Mangrove planting strategies should consider the optimal ratio between the area of tidal flats and the area of mangroves. Ocean Coast. Manag. 213:105875. doi: 10.1016/j. ocecoaman.2021.105875

Yasué, M. (2006). Environmental factors and spatial scale influence shorebirds responses to human disturbance. Biol. Conserv. 128, 47-54. doi: 10.1016/j. biocon.2005.09.015

Yasué, M., and Dearden, P. (2009). The importance of supratidal habitats for wintering shorebirds and the potential impacts of shrimp aquaculture. Environ. Manag. 43, 1108-1121. doi: 10.1007/s00267-008-9255-7

Zhai, L., Bo, Z., Shouraseni, S. R., Douglas, O. F., and Leonel, S. L. S. (2019). Remote sensing of unhelpful resilience to sea level rise caused by mangrove expansion: a case study of islands in Florida Bay, USA. Ecol. Indic. 97, 51-58. doi: 10.1016/j.ecolind.2018.09.063

Zhang, C., Yuan, Y., Zeng, G., Liang, J., Guo, S., Huang, L., et al. (2016). Influence of hydrological regime and climatic factor on waterbird abundance in Dongting Lake Wetland, China: implications for biological conservation. Ecol. Eng. 90, 473-481. doi: 10.1016/j.ecoleng.2016.01.076

Zhang, M., Hong, Y., Zou, F., Zhang, Q., Fan, H., Chan, S., et al. (2019). Response of shorebird habitat selection to coastal reclamation and urbanization in an extensively developed delta: a case study in Macao, China. Ocean Coast. Manag. 179, 1-9. doi: 10.1016/j.ocecoaman.2019.104871

Zou, F., Zhang, H., Tom, D., Yang, Q., Cai, J., Zhang, W., et al. (2008). The effects of benthos and wetland area on shorebird abundance and species richness in coastal mangrove wetlands of Leizhou Peninsula, China. For. Ecol. Manag. 255, 3813-3818. doi: 10.1016/j.foreco.2008.03.020

Conflict of Interest: ZD and SL were employed by the company Xiyan Natural Resources Technology (Guangzhou) Co., Ltd.

The remaining authors declare that the research was conducted in the absence of any commercial or financial relationships that could be construed as a potential conflict of interest.

Publisher's Note: All claims expressed in this article are solely those of the authors and do not necessarily represent those of their affiliated organizations, or those of the publisher, the editors and the reviewers. Any product that may be evaluated in this article, or claim that may be made by its manufacturer, is not guaranteed or endorsed by the publisher.

Copyright (c) 2022 Yang, Duan, Li, Zhang, Qu, Hua, Niu, Hu and Yu. This is an open-access article distributed under the terms of the Creative Commons Attribution License (CC BY). The use, distribution or reproduction in other forums is permitted, provided the original author(s) and the copyright owner(s) are credited and that the original publication in this journal is cited, in accordance with accepted academic practice. No use, distribution or reproduction is permitted which does not comply with these terms. 